\title{
Light Absorption and Partitioning in Relation to Nitrogen Content in 'Fuji' Apple Leaves
}

\author{
Lailiang Cheng, ${ }^{1}$ Leslie H. Fuchigami, and Patrick J. Breen \\ Department of Horticulture, Oregon State University, Corvallis OR 97331
}

\begin{abstract}
AdDitional INDEX wORDS. $\mathrm{CO}_{2}$ assimilation, electron transport, Malus sylvestris var. domestica, nonphotochemical quenching, photosynthetic photon flux, PSII efficiency

Abstract. Bench-grafted 'Fuji' apple [Malus sylvestris (L.) Mill. var.domestica (Borkh.) Mansf.] trees on Malling 26 (M.26) rootstocks were fertigated for 6 weeks with $\mathrm{N}$ concentrations ranging from 0 to $20 \mathrm{~mm}$. These treatments produced levels of leaf $\mathrm{N}$ ranging from 0.9 to $4.3 \mathrm{~g} \cdot \mathrm{m}^{-2}$. Over this range, leaf absorptance increased curvilinearly from $74.8 \%$ to $92.5 \%$. The light saturation point for $\mathrm{CO}_{2}$ assimilation expressed on the basis of absorbed light increased linearly at first with increasing leaf $\mathrm{N}$, then reached a plateau at a leaf $\mathrm{N}$ content of $\approx 3 \mathrm{~g} \cdot \mathrm{m}^{-2}$. Under high light conditions (photosynthetic photon flux of 1500 $\mu \mathrm{mol} \cdot \mathrm{m}^{-2} \cdot \mathrm{s}^{-1}$ ), the amount of absorbed light in excess of that required to saturate $\mathrm{CO}_{2}$ assimilation decreased with increasing leaf N. Chlorophyll fluorescence measurements revealed that the maximum photosystem II (PSII) efficiency of dark-adapted leaves was relatively constant over the leaf $\mathrm{N}$ range, except for a slight decrease at the lower end. As leaf $\mathrm{N}$ increased, nonphotochemical quenching declined under high light, and there was an increase in the efficiency with which the absorbed photons were delivered to open PSII centers. The photochemical quenching coefficient remained high except for a decrease at the lower end of the leaf $\mathrm{N}$ range. Actual PSII efficiency increased curvilinearly with increasing leaf $\mathrm{N}$, and was highly correlated with light-saturated $\mathrm{CO}_{2}$ assimilation. The fraction of absorbed light potentially going into singlet oxygen formation was estimated to be $\approx \mathbf{1 0 \%}$, regardless of leaf $\mathrm{N}$ status. It was concluded that there was more excess absorbed light in low N leaves than in high N leaves under high light conditions. Nonphotochemical quenching was enhanced with decreasing leaf $\mathbf{N}$ to reduce both the PSII efficiency and the probability of damage from photooxidation by excess absorbed light.
\end{abstract}

Carbon dioxide assimilation is closely related to leaf nitrogen content because the large number of enzymes or proteins involved in the process of photosynthesis account for the majority of leaf $\mathrm{N}$. A curvilinear relationship has been found between leaf $\mathrm{N}$ and lightsaturated $\mathrm{CO}_{2}$ assimilation in apple leaves (Malus sylvestris var. domestica) (Cheng and Fuchigami, 2000). The decreased activation state of ribulose 1,5-bisphosphate carboxylase/oxygenase (rubisco) with increasing leaf $\mathrm{N}$ accounts for this curvilinearity (Cheng, 1999). Low total rubisco activity and high rubisco activation state in low Nleaves indicate that light-saturated $\mathrm{CO}_{2}$ assimilation is mainly limited by the amount of rubisco. However, low $\mathrm{N}$ leaves have low chlorophyll content. Thus, it is unclear whether decreased light absorption also limits $\mathrm{CO}_{2}$ assimilation in low $\mathrm{N}$ leaves.

The input of light energy into the photosynthetic system involves processes whereby quantum energy is captured by antenna pigments and excess excitation energy is dissipated. Finally, a proportion of the absorbed quantum energy is used in photosynthetic electron transport (Horton et al., 1996). At steady state photosynthesis, light input flux is coordinated with $\mathrm{CO}_{2}$ input in such a way that the capacity to make triose phosphate by photosynthetic carbon reduction balances the capacity to use triose phosphate in endproduct synthesis (Sharkey, 1990; Woodrow and Berry, 1988). When photosynthetic photon flux $(P P F)$ is in excess of that required for photosynthetic electron transport, photosystem II (PSII) must be down-regulated to match rubisco activity. Both electron transport and total rubisco activity are correlated linearly to leaf $\mathrm{N}$, indicating that light and dark reactions are altered equally by leaf $\mathrm{N}$ (Evans, 1996). However, the input of $P P F$ fluctuates dramatically during a

Received for publication 15 Nov. 1999. Accepted for publication 27 Apr. 2000. This research was supported, in part, by the Washington Tree Fruit Research Commission and Pacific Northwest Nursery Improvement Institute. We gratefully acknowledge the helpful review comments of Bruce Schaffer and an anonymous reviewer, and the editorial assistance of Priscilla Licht. The cost of publishing this paper was defrayed in part by the payment of page charges. Under postal regulations, this paper therefore must be hereby marked advertisement solely to indicate this fact. ${ }^{1}$ Corresponding author. Current address: Department of Horticulture, Cornell University, Ithaca, NY 14853; e-mail: LC89@Cornell.edu. clear day, with maximum $P P F$ occurring at midday under cloudless conditions.

Chlorophyll content is correlated linearly with $\mathrm{N}$ content in apple leaves (Cheng and Fuchigami, 2000). Decreased light absorption by antenna pigments in low $\mathrm{N}$ leaves, however, may not be sufficient to deal with the large fluctuation of $P P F$ under natural conditions. Quantum efficiency must be maximized under low $P P F$, yet leaves must be protected from excessive light damage under high $P P F$. Because low $\mathrm{N}$ leaves have low rubisco activity, which requires low electron transport, there may be more excess excitation energy in low $\mathrm{N}$ leaves than high $\mathrm{N}$ leaves under high $P P F$ conditions.

When plants are exposed to $P P F \mathrm{~s}$ in excess of those that can be used in photosynthetic electron transport, excess excitation energy can be dissipated as heat in the antenna pigments of PSII (DemmigAdams et al., 1997; Gilmore, 1997). Analyzing changes in chlorophyll fluorescence emission via a pulse-modulated fluorescence monitoring system (Schreiber et al., 1994) has been used increasingly to estimate the activity of thermal dissipation processes, as well as photosynthetic electron transport in leaves (Demmig-Adams et al., 1996; Genty et al., 1989). Thermal dissipation of excess excitation energy has been studied extensively under high light conditions (Adams and Demmig-Adams, 1992; Demmig-Adams and Adams, 1996; Demmig-Adams et al., 1996) and low temperature stress (Adams and Demmig-Adams, 1995; Adams et al., 1995a, 1995b; Gilmore and Björkman, 1994a, 1994b; Verhoeven et al., 1996). However, information is limited about thermal dissipation of excitation energy in response to leaf $\mathrm{N}$ status (Khamis etal., 1990; Verhoeven etal., 1997). Therefore, the objectives of this study were to determine, under high $P P F$ conditions, if there is more excess absorbed $P P F$ in low $\mathrm{N}$ leaves than in high $\mathrm{N}$ leaves and how absorbed $P P F$ is partitioned into photochemical and nonphotochemical processes in response to $\mathrm{N}$ content in apple leaves.

\section{Materials and Methods}

Plant Material. 'Fuji' apple trees on Malling 26 (M.26) rootstocks were used in this study. Bench-grafting was done in late 
March 1997 and each grafted tree was planted immediately into a 3.8-L pot containing a medium of 1 peat : 2 pumice : 1 sandy loam soil (by volume). The plants were grown in a lathhouse until early June. During this period, beginning from budbreak in early May, they were fertigated every 2 weeks with $150 \mathrm{mg} \cdot \mathrm{L}^{-1} \mathrm{~N}$, using Plantex $20 \mathrm{~N}-10 \mathrm{P}_{2} \mathrm{O}_{5}-20 \mathrm{~K}_{2} \mathrm{O}$ water-soluble fertilizer with micronutrients (Plantex Corp., Ontario, Canada). When the scion shoots were $\approx 15$ $\mathrm{cm}$ tall, plants were selected for uniformity, and moved to full sun. Thereafter, they were fertigated weekly with Plantex for 3 weeks. Beginning 30 June, plants were fertigated twice weekly with $\mathrm{N}$ at 0 , $2.5,5.0,7.5,10.0,15.0$ or $20.0 \mathrm{~mm}$ (from $\mathrm{NH}_{4} \mathrm{NO}_{3}$ ) by applying 300 $\mathrm{mL}$ of a modified Hoagland's solution to each pot (Cheng and Fuchigami, 2000). There were four replications for each $\mathrm{N}$ treatment in a completely randomized design. Plants were subirrigated with a saucer placed at the bottom of each pot. After 6 weeks, recent fully expanded leaves were selected for gas exchange and chlorophyll fluorescence measurements.

MEASUREMENTS OF LEAF ABSORPTANCE, GAS EXCHANGE, AND CHLOROPHYLL FLUORESCENCE. A spectroradiometer with the 180012S integrating sphere attachment (LI-1800; LI-COR Inc., Lincoln, Nebr.) was used to measure leaf reflectance and transmittance. For each leaf, both a reference scan and a sample scan of reflectance or transmittance were made from 400 to $700 \mathrm{~nm}$, at 1-nm intervals. The sample scan was divided by its corresponding reference scan, and integrated over the wavelength range to obtain the average reflectance or transmittance. Leaf absorptance was calculated as 1 reflectance - transmittance.

Carbon dioxide assimilation and PSII efficiency were monitored concurrently with a system that combined a CIRAS-1 gas exchange system (PP Systems, Hitchin, Herts., U.K.) and an FMS-1 pulsemodulated fluorometer (Hansatech Instruments Ltd., King's Lynn, Norfolk, U.K.). The light- and temperature-controlled cuvette of the CIRAS-1 system was modified so that the fiber optic of the FMS1 was inserted into the cuvette at a $60^{\circ}$ angle. This did not significantly interfere with $P P F$ distribution at the leaf surface, yet it allowed delivery of a saturation pulse of actinic light and detection of fluorescence signals. Measurements of $\mathrm{CO}_{2}$ assimilation and PSII efficiency in response to $P P F$ were made in descending order, at incident $P P F$ s of $1500,1150,850,600,400,250,150,75$, and 0 $\mu \mathrm{mol} \cdot \mathrm{m}^{-2} \cdot \mathrm{s}^{-1}$, at ambient $\mathrm{CO}_{2}\left(350 \mathrm{mg} \cdot \mathrm{L}^{-1}\right)$ and $\mathrm{O}_{2}(21 \%)$. The two light sensors in the cuvette were not located exactly at the leaf surface, therefore, the actual corresponding incident $P P F$ s at the leaf surface level were $1645,1225,907,640,425,267,160,80$, and 0 $\mu \mathrm{mol} \cdot \mathrm{m}^{-2} \cdot \mathrm{s}^{-1}$, as measured with a recently calibrated quantum sensor (LI-190SA; LI-COR). At each PPF, $\mathrm{CO}_{2}$ assimilation and actual PSII efficiency were recorded after reaching steady state. Actual PSII efficiency was measured in essentially the same way as under natural $P P F$ conditions described below.

Total electron transport was calculated as incident $P P F \times$ absorptance $\times 0.5 \times$ PSII efficiency (Krall and Edwards, 1992). Responses of $\mathrm{CO}_{2}$ assimilation and actual PSII efficiency to $P P F$ were measured on 20 leaves with different $\mathrm{N}$ contents. Each photosynthetic light response curve was fitted to the following negative exponential model by nonlinear regression analysis, using the SAS procedure NLIN (SAS Institute Inc., Cary, N.C.) with the Marquardt option (Hampson et al., 1996): $\mathrm{A}=\mathrm{Rd}+\mathrm{S}\left(1-e^{-\mathrm{G} \times P P F}\right)$, where $\mathrm{A}$ is $\mathrm{CO}_{2}$ assimilation, $\mathrm{Rd}$ is dark respiration, $\mathrm{S}$ is the asymptotic maximum, $e$ is the base of natural $\log , \mathrm{G}$ is the rate of approach to the maximum, and $P P F$ is photosynthetic photon flux. The light saturation point for $\mathrm{CO}_{2}$ assimilation was estimated as the $P P F$ at which $95 \%$ of the light-saturated assimilation rate was attained.

The relationship between leaf $\mathrm{N}$ and chlorophyll fluorescence parameters was studied on 28 leaves with a wide range of leaf $\mathrm{N}$ contents either predawn or at a $P P F$ of $1500 \pm 50 \mu \mathrm{mol} \cdot \mathrm{m}^{-2} \cdot \mathrm{s}^{-1}$ at noon, under natural conditions, using the FMS-1 fluorometer. The fiber optic of the FMS-1 was positioned using the $P P F /$ temperature leaf clip at a $60^{\circ}$ angle from the upper surface of the leaf, and the distance between the fiber optic and the leaf surface was kept constant for both predawn and noon measurements. Maximum fluorescence $(\mathrm{Fm})$ and minimum fluorescence (Fo) of dark-adapted leaves were measured predawn. For leaves exposed to natural sunlight, steady state fluorescence (Fs) was monitored to ensure it was stable before a reading was taken. Maximum fluorescence $\left(\mathrm{Fm}^{\prime}\right)$ under natural light exposure was obtained by imposing a 1-s saturating flash of $\approx 18,000 \mu \mathrm{mol} \cdot \mathrm{m}^{-2} \cdot \mathrm{s}^{-1} P P F$ at the end of the fiber optic to the leaf in order to reduce all the PSII centers. To determine the minimum fluorescence (Fo') under natural light exposure, a black envelope was placed around the leaf while a far-red light was
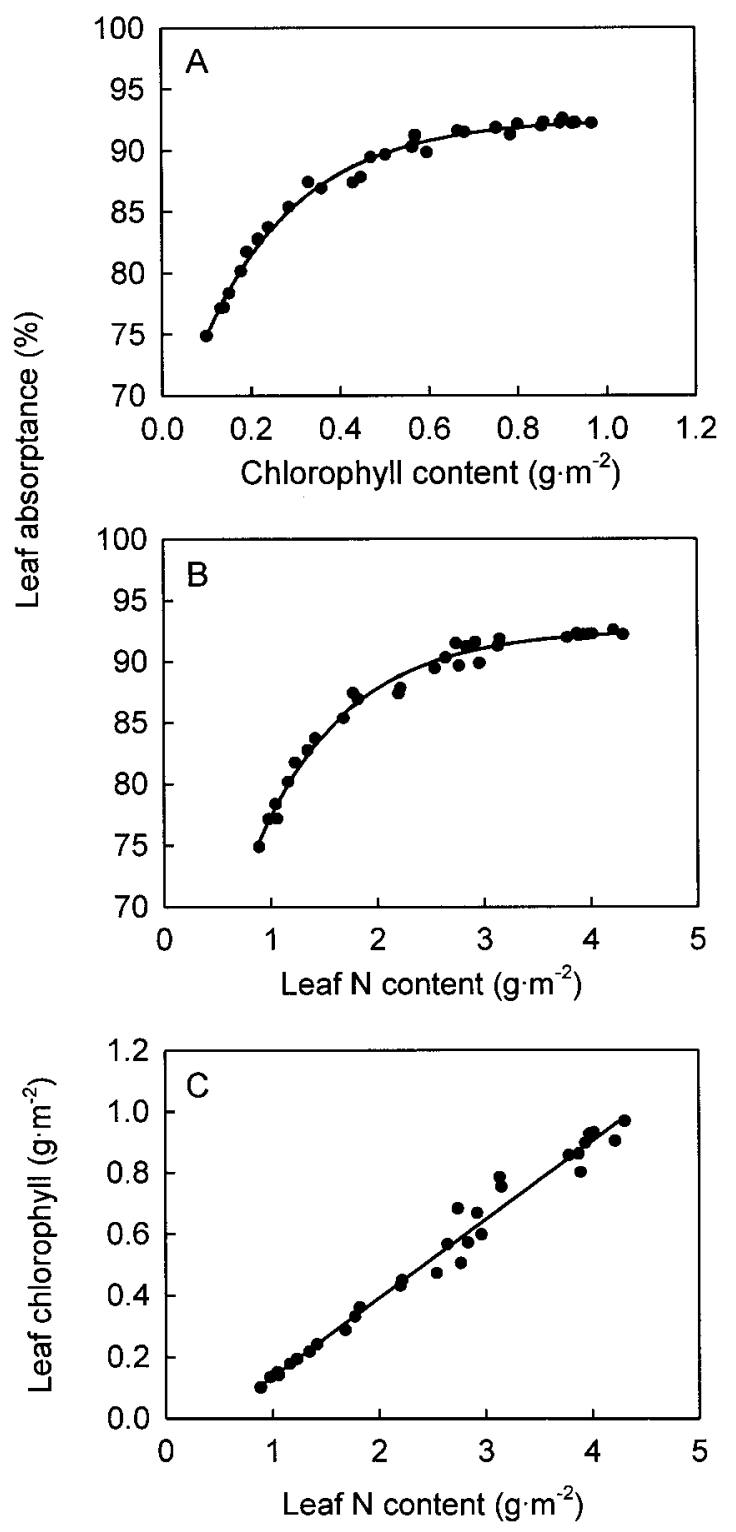

Fig. 1. Leaf absorptance in relation to (A) chlorophyll content and (B) nitrogen content, and $(\mathbf{C})$ the relationship between leaf $\mathrm{N}$ and chlorophyll content in apple leaves. Regression equations: $(\mathbf{A}) \mathrm{Y}=27.94\left(1-e^{-4.594 \mathrm{X}}\right)+64.58\left(R^{2}=0.99, P=\right.$ $0.0001),(\mathbf{B}) \mathrm{Y}=48.39\left(1-e^{-1.153 \mathrm{X}}\right)+44.18\left(R^{2}=0.99, P=0.0001\right)$, and $(\mathbf{C}) \mathrm{Y}=$ $-0.122+0.256 \mathrm{X}\left(R^{2}=0.98, P=0.0001\right)$. 

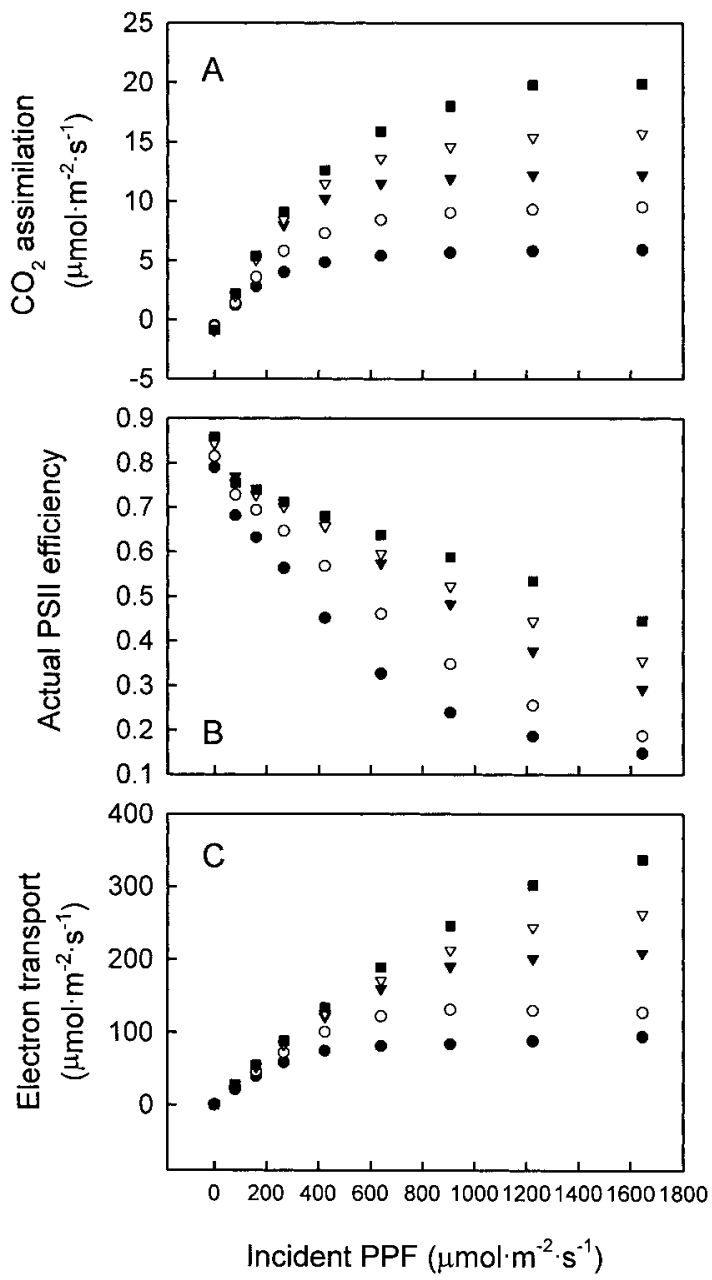

Fig. 2. (A) Carbon dioxide assimilation, (B) actual PSII efficiency, and (C) electron transport of apple leaves in response to incident $P P F$. Measurements were made at a $\mathrm{CO}_{2}$ concentration of $350 \pm 2 \mathrm{mg} \cdot \mathrm{L}^{-1}$, a leaf temperature of $25 \pm 0.2^{\circ} \mathrm{C}$, and an ambient water vapor pressure of $1.55 \pm 0.2 \mathrm{kPa}$. Leaf $\mathrm{N}$ content $\left(\mathrm{g} \cdot \mathrm{m}^{-2}\right)$ is 1.06 $(\mathbf{O}), 1.35(\bigcirc), 1.82(\boldsymbol{\nabla}), 2.77(\nabla)$, and $4.02(\mathbf{\square})$

switched on to rapidly oxidize PSII by drawing electrons from PSII to PSI. The maximum PSII efficiency of dark-adapted leaves was calculated as Fv/Fm $=(\mathrm{Fm}-\mathrm{Fo}) / \mathrm{Fm}$ (For fluorescence nomenclature see van Kooten and Snel, 1990).

For leaves exposed to natural sunlight, thermal dissipation was estimated from nonphotochemical quenching as Fm/Fm'-1 (SternVolmer quenching, or NPQ; see Bilger and Björkman, 1990) or nonphotochemical quenching coefficient: $\mathrm{qN}=1-\left(\mathrm{Fm}^{\prime}-\mathrm{Fo}^{\prime}\right) /(\mathrm{Fm}$ - Fo). The efficiency of open PSII centers under natural light exposure $\left(\mathrm{Fv}^{\prime} / \mathrm{Fm}^{\prime}\right)$ was calculated as $\left(\mathrm{Fm}^{\prime}-\mathrm{Fo}^{\prime}\right) / \mathrm{Fm}^{\prime}$. This is also referred to as the efficiency with which excitation energy is delivered to open PSII centers, or the efficiency of excitation capture by PSII. The photochemical quenching coefficient qP was (Fm' - Fs)/ $\left(\mathrm{Fm}^{\prime}-\mathrm{Fo}^{\prime}\right)$. The degree of closure of PSII reaction centers was estimated as $1-\mathrm{qP}$. Actual PSII efficiency was $\left(\mathrm{Fv}^{\prime} / \mathrm{Fm}^{\prime}\right) \times \mathrm{qP}=$ $\left(\mathrm{Fm}^{\prime}-\mathrm{Fs}\right) / \mathrm{Fm}^{\prime}$ (Genty et al., 1989). The percentage of absorbed light potentially going into singlet oxygen formation was estimated as $\left(\mathrm{Fv}^{\prime} / \mathrm{Fm}^{\prime}\right) \times(1-\mathrm{qP})$ (Demmig-Adams et al., 1996).

LEAF N AND CHLOROPHYLL ANALYSIS. After all the above measurements, leaf area was determined with a leaf area meter (LI-3000, LICOR). Leaves were frozen in liquid nitrogen and stored at $-80^{\circ} \mathrm{C}$ until freeze-dried. Leaf $\mathrm{N}$ content was determined by the Kjeldahl procedure (Schuman et al., 1973). Leaf chlorophyll content was measured according to Arnon (1949).

\section{Results}

LEAF ABSORPTANCE IN RESPONSE TO LEAF N. A curvilinear relationship was found between leaf chlorophyll content and leaf absorptance (Fig. 1A). Leaf absorptance increased almost linearly with increasing leaf chlorophyll content up to $\approx 0.3 \mathrm{~g} \cdot \mathrm{m}^{-2}$, then began to level off with a further rise in leaf chlorophyll content. Leaf absorptance also showed a curvilinear response to leaf $\mathrm{N}$ (Fig. 1B) because chlorophyll content was correlated linearly with leaf N (Fig. 1C). Although leaf $\mathrm{N}$ content varied from 0.9 to $4.3 \mathrm{~g} \cdot \mathrm{m}^{-2}$, leaf absorptance increased only from $74.8 \%$ to $92.5 \%$.

RESPONSE OF $\mathrm{CO}_{2}$ ASSIMILATION AND ELECTRON TRANSPORT TO PPF AND EXCESS ABSORBED PPF IN RELATION TO LEAF N. For all leaves, $\mathrm{CO}_{2}$ assimilation increased with increasing $P P F$ up to a saturation point, then showed little response to any further rise in $P P F$ (Fig. 2A). Actual PSII efficiency decreased with increasing PPF (Fig. 2B). Calculated total electron transport showed a response to $P P F$ similar to that of $\mathrm{CO}_{2}$ assimilation (Fig. 2C). At each given incident $P P F$, low $\mathrm{N}$ leaves had lower $\mathrm{CO}_{2}$ assimilation, actual PSII efficiency, and total electron transport than high $\mathrm{N}$ leaves. A positive correlation was found between actual PSII efficiency and $\mathrm{CO}_{2}$ assimilation under light-saturated conditions (Fig. 3A), and also between total electron transport and $\mathrm{CO}_{2}$ assimilation (Fig. 3B).

After accounting for leaf absorptance, $\mathrm{CO}_{2}$ assimilation in response to absorbed $P P F$ was still dependent on leaf $\mathrm{N}$ (Fig. 4).

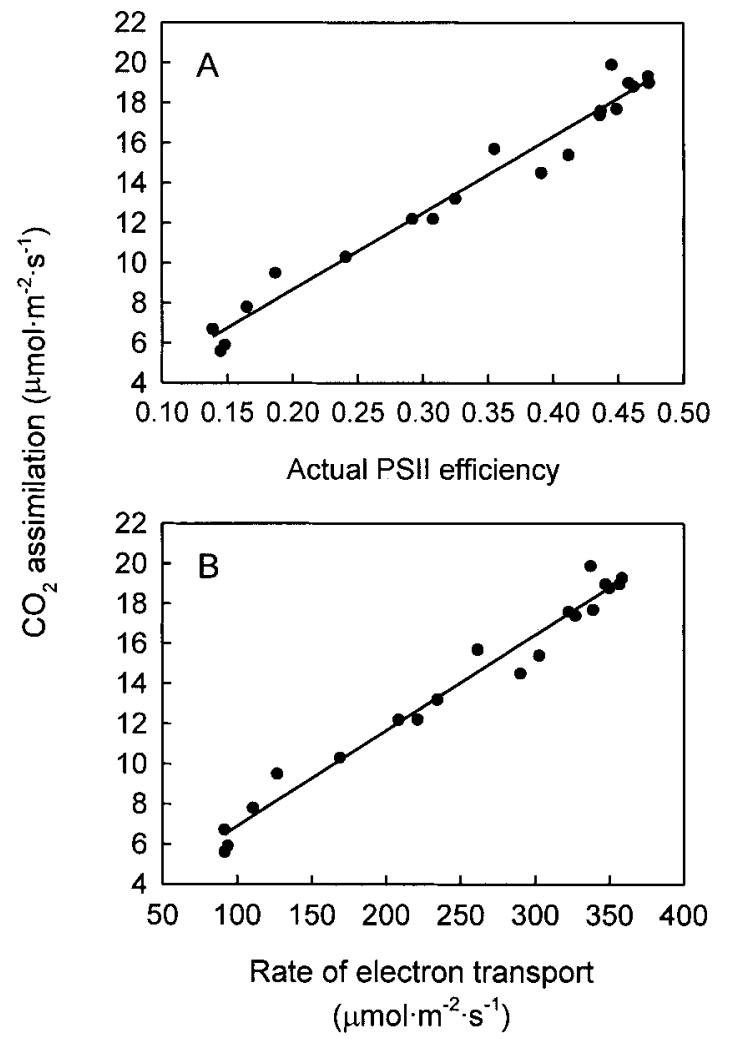

Fig. 3. Carbon dioxide assimilation in relation to (A) actual PSII efficiency and (B) total electron transport in apple leaves at an incident $P P F$ of $1645 \mu \mathrm{mol} \cdot \mathrm{m}^{-2} \cdot \mathrm{s}^{-1}$. Regression equations: (A) $\mathrm{Y}=0.98+38.28 \mathrm{X}\left(R^{2}=0.97, P=0.0001\right)$, and (B) $\mathrm{Y}$ $=2.11+0.0476 \mathrm{X}\left(R^{2}=0.97, P=0.0001\right)$. Measurement conditions were the same as in Fig. 2. 


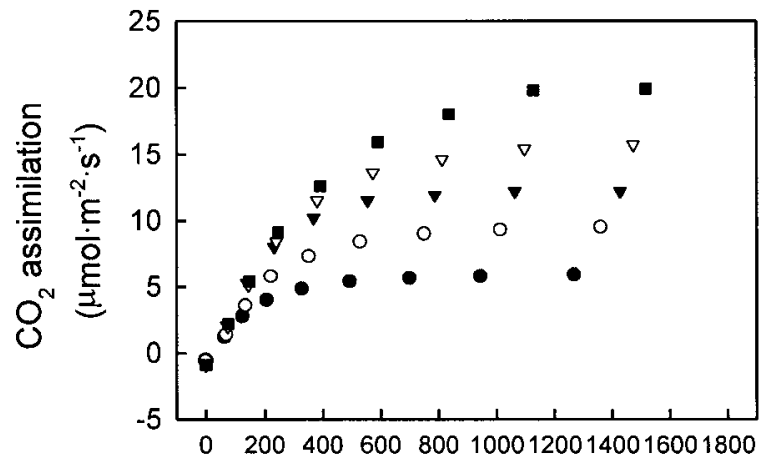

Absorbed PPF $\left(\mu \mathrm{mol} \cdot \mathrm{m}^{-2} \cdot \mathrm{s}^{-1}\right)$

Fig. 4. Carbon dioxide assimilation of apple leaves in response to absorbed $P P F$ Leaf $\mathrm{N}$ content $\left(\mathrm{g} \cdot \mathrm{m}^{-2}\right)$ is $1.06(\mathbf{\bullet}), 1.35(\mathrm{O}), 1.82(\boldsymbol{\nabla}), 2.77(\nabla)$, and $4.02(\mathbf{\square})$. Measurement conditions were the same as in Fig. 2.

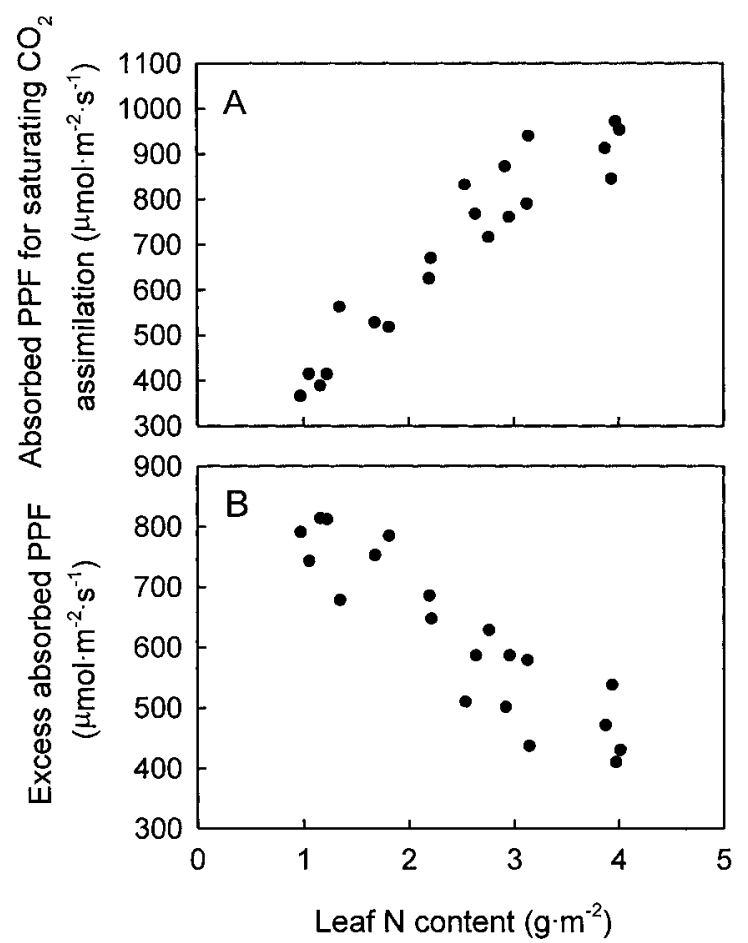

Fig. 5. Relationship between leaf $\mathrm{N}$ content and (A) the light saturation point expressed as absorbed $P P F$, and $(\mathbf{B})$ excess absorbed $P P F$ at an incident $P P F$ of $1500 \mu \mathrm{mol} \cdot \mathrm{m}^{-2} \cdot \mathrm{s}^{-1}$. Excess absorbed $P P F$ was calculated as the difference between the actual absorbed $P P F$ and the light saturation point expressed as absorbed $P P F$. Measurement conditions were the same as in Fig. 2.

Quantum yield for $\mathrm{CO}_{2}$ assimilation remained relatively unchanged, except for a slight decrease at the lower end of the leaf $\mathrm{N}$ range (data not presented). The light saturation point, expressed as absorbed $P P F$, increased at first with increasing leaf $\mathrm{N}$, then leveled off at a leaf $\mathrm{N}$ content of $\approx 3 \mathrm{~g} \cdot \mathrm{m}^{-2}$ (Fig. 5A). At an incident $P P F$ of 1500 $\mu \mathrm{mol} \cdot \mathrm{m}^{-2} \cdot \mathrm{s}^{-1}$, the amount of excess absorbed light (calculated as the difference between the actual absorbed $P P F$ and the light saturation point expressed as absorbed $P P F$ ) decreased with increasing leaf $\mathrm{N}$ (Fig. 5B).

CHLOROPHYLL FLUORESCENCE PARAMETERS IN RELATION TO LEAF N. Maximum PSII efficiency (Fv/Fm) of dark-adapted leaves remained relatively unchanged, except for a slight decrease at the lower end of the leaf $\mathrm{N}$ range (Fig. 6A). Thermal dissipation of excitation energy, indicated by both nonphotochemical quenching (NPQ) and the nonphotochemical quenching coefficient (qN) decreased with increasing leaf N (Fig. 6B and C). Correspondingly, the efficiency of excitation capture ( $\left.\mathrm{Fv}^{\prime} / \mathrm{Fm}^{\prime}\right)$ by open PSII reaction centers increased with increasing leaf $\mathrm{N}$ up to nearly $3 \mathrm{~g} \cdot \mathrm{m}^{-2}$, then leveled off with a further rise in leaf N (Fig. 6D). Photochemical quenching $(\mathrm{qP})$ remained high except for a decrease at the lower end of the leaf $\mathrm{N}$ range (Fig. 6E). This corresponded with a low degree of closure of PSII (1-qP) over the leaf N range, except in extremely low $\mathrm{N}$ leaves (Fig. 6G). Actual PSII efficiency increased with increasing leaf $\mathrm{N}$ at first, then leveled off with further increases in leaf N (Fig. 6F). The fraction of absorbed light potentially going into singlet oxygen formation remained at $\approx 10 \%$ over the leaf $\mathrm{N}$ range examined (Fig. 6H).

\section{Discussion}

Leaf light absorption and partitioning into different pathways may be summarized as in Fig. 7. Part of the incident light is either reflected or transmitted; only a proportion is absorbed by lightharvesting pigments. Depending on the amount of absorbed PPF, either most or only a proportion of it is delivered to open PSII centers. At low PPFs, most of the absorbed light is used in photosynthetic electron transport; any dissipation of excitation energy via an alternative pathway would decrease the efficiency of PSII. At high PPFs, however, not all the absorbed light can be used in photosynthetic electron transport. The excess excitation energy must then be dissipated either through a harmless thermal process or by formation of toxic, activated-oxygen species (Demmig-Adams et al., 1996, 1997).

Apple trees do not have the rapid, active leaf movement to evade excessive light that plant species with pulvinar tissues have (e.g., Leguminosae and Oxalidaceae; reviewed in Koller, 1990). Decreasing the absorption of light by reducing chlorophyll content is the first line of defense for protecting leaves from photooxidation in response to low $\mathrm{N}$ availability. This was suggested in studies with maize (Zea mays L.) (Khamis et al., 1990) and spinach (Spinacia oleracea L.) (Verhoeven et al., 1997), although leaf absorptance was not measured in either experiment. A decrease in chlorophyll content provides a coarse regulatory mechanism for reducing light absorption at each given incident $P P F$. Decreased light absorption alone, however, is not enough for low $\mathrm{N}$ leaves to cope with high light because light absorption is not reduced proportionally when leaf $\mathrm{N}$ decreases (Fig. 1B). In our experiment, under high light conditions, low $\mathrm{N}$ leaves had more excess absorbed light than high $\mathrm{N}$ leaves (Fig. 5B) because photosynthetic electron transport used only a small percentage of the absorbed light.

Actual PSII efficiency is determined by both the photochemical quenching $(\mathrm{qP})$ and the efficiency of excitation capture $\left(\mathrm{Fv}^{\prime} / \mathrm{Fm}^{\prime}\right)$ by open PSII centers (Genty et al., 1989). When there is excess absorbed light, actual PSII efficiency can be reduced by two processes to match photosynthetic electron transport. One process is to decrease the efficiency with which excitation energy is delivered to open PSII centers via thermal dissipation of excitation energy in the antenna pigment complexes (Demmig-Adams et al., 1995, 1996; Genty et al., 1990). The alternative process is to close PSII reaction centers by overreducing the electron acceptors of PSII. In the latter case, a transient backlog of excitation energy occurs. This leads to increased formation of triplet excited chlorophyll, which has the potential to react with oxygen to form toxic singlet oxygen (Asada, 1996). 

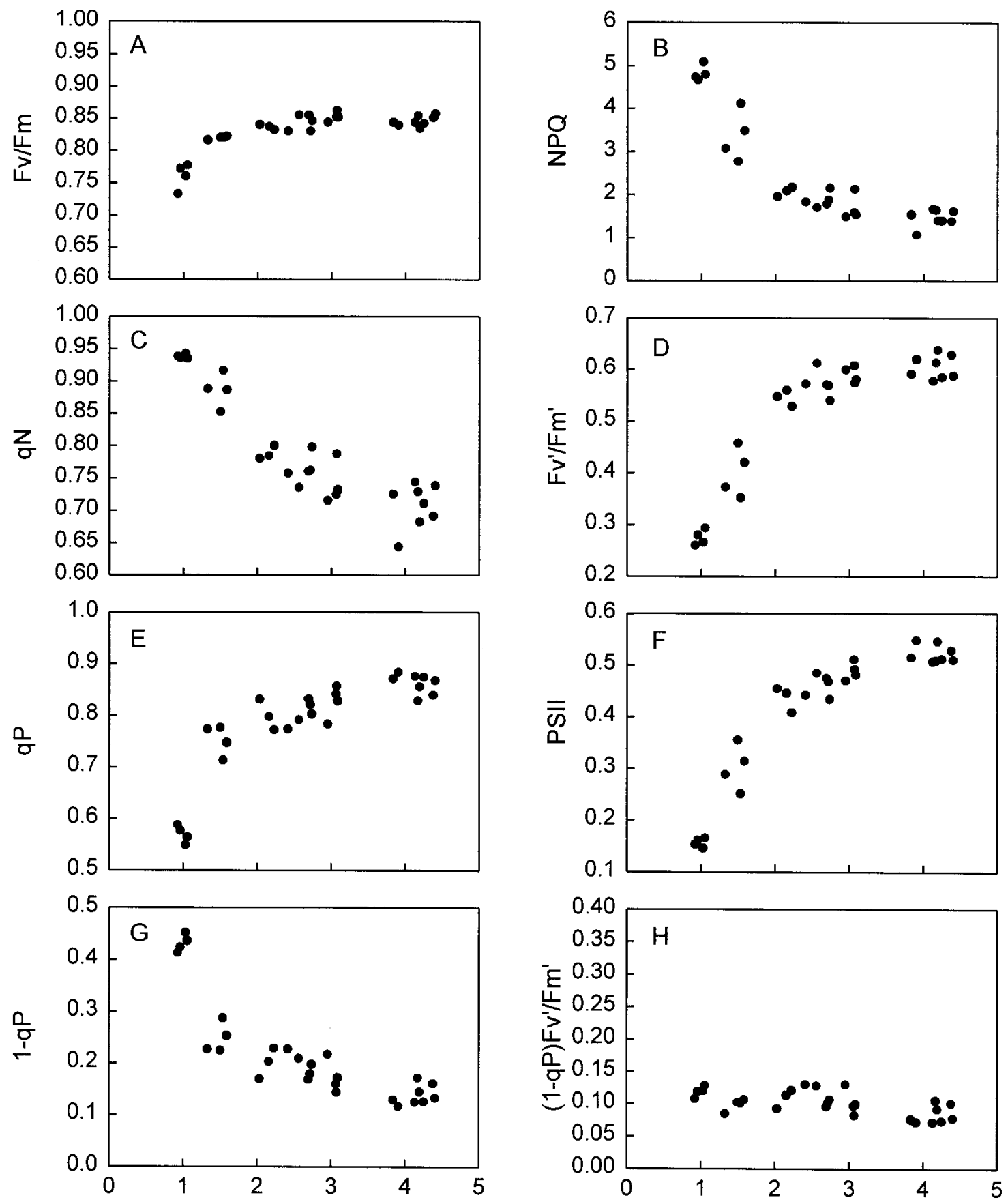

\section{Leaf $\mathrm{N}$ content $\left(\mathrm{g} \cdot \mathrm{m}^{-2}\right)$}

Fig. 6. Chlorophyll fluorescence parameters in relation to $\mathrm{N}$ content in apple leaves. (A) Maximum PSII efficiency (Fv/Fm) of dark-adapted leaves was measured predawn on 11 Aug. 1997. The remaining parameters were measured at a $P P F$ of $1500 \pm 50 \mu \mathrm{mol} \cdot \mathrm{m}^{-2} \cdot \mathrm{s}^{-1}$ and air temperature of $29 \pm 1^{\circ} \mathrm{C}$ at noon. $(\mathbf{B}) \mathrm{NPQ}=$ nonphotochemical quenching $\left(\mathrm{Fm} / \mathrm{Fm}^{\prime}-1\right)$, (C) qN = nonphotochemical quenching coefficient $\left[1-\left(\mathrm{Fm}^{\prime}-\mathrm{Fo}^{\prime}\right) /(\mathrm{Fm}-\mathrm{Fo})\right]$, (D) $\mathrm{Fv}^{\prime} / \mathrm{Fm}^{\prime}=$ efficiency of excitation capture by open PSII centers $\left[\left(\mathrm{Fm}^{\prime}-\mathrm{Fo}^{\prime}\right) / \mathrm{Fm}^{\prime}\right]$, (E) qP = photochemical quenching coefficient $\left[\left(\mathrm{Fm}^{\prime}-\mathrm{Fs}\right) /\left(\mathrm{Fm}^{\prime}-\mathrm{Fo}^{\prime}\right)\right],(\mathrm{F}) \mathrm{PSII}=$ actual PSII efficiency $\left.\left[\left(\mathrm{Fm}^{\prime}-\mathrm{Fs}\right) / \mathrm{Fm}^{\prime}\right)\right],(\mathrm{G}) 1-\mathrm{qP}=\operatorname{degree}$ of closure of PSII centers, and $(\mathrm{H})\left(\mathrm{Fv}^{\prime} / \mathrm{Fm}^{\prime}\right)(1-\mathrm{qP})=$ the fraction of absorbed $P P F$ potentially going into singlet oxygen formation.

Thermal dissipation can safely remove excess excitation energy before it reaches PSII reaction centers, thus protecting these centers by preventing an accumulation of reduced electron acceptors of PSII (Demmig-Adams et al., 1996, 1997). In our experiment, thermal dissipation of excitation energy, indicated by nonphotochemical quenching, was enhanced in low $\mathrm{N}$ leaves in response to more excess absorbed light, compared with high $\mathrm{N}$ leaves under high light (Figs. 6B and C). This increase in thermal dissipation was so effective in decreasing the efficiency for delivering excitation energy to open PSII centers (Fig. 6D) that the fraction of absorbed light potentially going into singlet oxygen formation remained at $\approx 10 \%$ across the leaf $\mathrm{N}$ range (Fig. $6 \mathrm{H})$. In response to $\mathrm{N}$ deficiency, enhancement of thermal dissipation of excitation energy in maize leaves overcompensated for the decrease in photosynthetic electron transport, such that the primary electron acceptor of PSII remained more oxidized in N- 


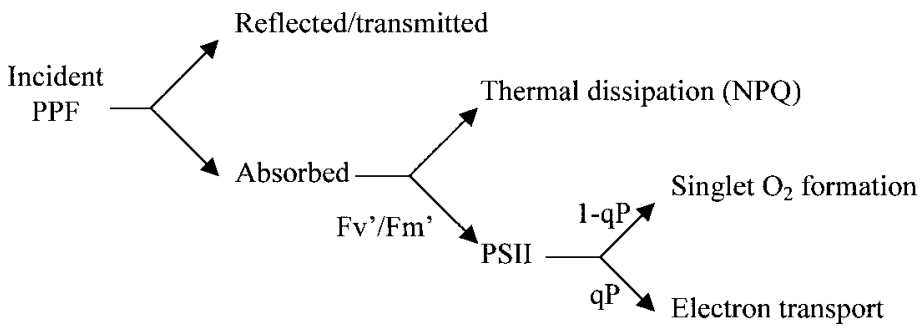

Fig. 7. Leaf light absorption and partitioning (modified from Demmig-Adams et al., 1996, 1997). Thermal dissipation of excitation energy is indicated by NPQ (nonphotochemical quenching of chlorophyll fluorescence). $\mathrm{Fv}^{\prime} / \mathrm{Fm}^{\prime}$ is the fraction of absorbed $P P F$ that is delivered to open PSII centers. Of the $P P F$ delivered to PSII, the proportion used in photosynthetic electron transport is $\mathrm{q} P$ (photochemical quenching coefficient); the rest $(1-\mathrm{qP})$ represents the fraction that potentially goes into singlet oxygen formation. The percentage of absorbed $P P F$ used in electron transport is the actual PSII efficiency $\left(\mathrm{Fv}^{\prime} / \mathrm{Fm}^{\prime}\right) \mathrm{qP}$ (Genty et al., 1989). The percentage of absorbed light potentially going into singlet oxygen formation is estimated as $\left(\mathrm{Fv}^{\prime} / \mathrm{Fm}^{\prime}\right)(1-\mathrm{qP})($ Demmig-Adams et al., 1996).

deficient plants than in N-replete controls (Khamis et al., 1990).

Under slowly developed water stress, nonphotochemical quenching increased in apple leaves (Massacci and Jones, 1990). Considerable evidence proves that increased thermal dissipation of excitation energy is an important photoprotective mechanism for plants responding to excess absorbed $P P F$, whether this results from increasing $P P F$ or decreased electron transport caused by environmental stress. In a natural setting, the plant's thermal dissipation of excess excitation energy was sufficient to remove excess absorbed $P P F$ and protect leaves from photooxidation (Demmig-Adams et al., 1995, 1996, 1997).

The photoprotective effect of thermal dissipation in response to $\mathrm{N}$ deficiency was also reflected in the maximum PSII efficiency of dark-adapted leaves. Except for a slight decrease at the lower end of the leaf $\mathrm{N}$ range, Fv/Fm of dark-adapted leaves remained relatively unchanged across the leaf $\mathrm{N}$ range (Fig. 6A). This decrease in Fv/Fm may have been caused by sustained xanthophyll cycle-dependent thermal dissipation during the night; PSII centers are not necessarily damaged by excess absorbed light (Adams and Demmig-Adams, 1994, 1995; Adams et al., 1995a, 1995b; Verhoeven et al., 1996, 1997). When plants growing in natural gaps of a tropical forest were exposed to direct sunlight for 1 to $2 \mathrm{~h}$ at midday, the decline in Fv/ Fm of dark-adapted leaves and subsequent recovery in the dark were correlated closely with the amount of zeaxanthin in leaves. This indicates that the decrease in Fv/Fm of dark-adapted leaves after midday direct sun exposure may also result from sustained xanthophyll cycle activity (Thiele et al., 1998).

Fv/Fm of dark-adapted apple leaves was not affected by water stress, but $\mathrm{CO}_{2}$ assimilation decreased (Massacci and Jones, 1990). Measuring Fv/Fm of dark-adapted leaves alone may not provide enough information on $\mathrm{CO}_{2}$ assimilation of the photosynthesis process. The linear relationship between actual PSII efficiency (Fm' - Fs) $/ \mathrm{Fm}^{\prime}$ and $\mathrm{CO}_{2}$ assimilation suggests that actual PSII efficiency may better indicate the rate of $\mathrm{CO}_{2}$ assimilation at a fixed $P P F$ level if partitioning of total photosynthetic electron transport into $\mathrm{CO}_{2}$ assimilation and photorespiration remains unchanged.

Thermal dissipation of excitation energy involves a xanthophyll cycle and a transthylakoid $\mathrm{pH}$ difference (Demmig-Adams et al., 1997; Gilmore, 1997). The xanthophyll cycle consists of lightdependent conversion between three xanthophylls in a cyclic reaction (Demmig-Adams et al., 1997). Under high PPF conditions, diepoxide violaxanthin $(\mathrm{V})$ is deepoxidized via the monoepoxide antheraxanthin (A) to the epoxide-free form zeaxanthin (Z). When $P P F$ decreases, epoxidation of $\mathrm{Z}$ occurs in the reverse direction to form $\mathrm{V}$ via $\mathrm{A}$. Nonphotochemical energy dissipation is correlated closely with the level of $\mathrm{Z}$ or $\mathrm{A}+\mathrm{Z}$; this relationship is speciesindependent(Demmig-Adams and Adams, 1996). A transthylakoid $\mathrm{pH}$ difference is required for activating the deepoxidase enzyme that converts $\mathrm{V}$ to $\mathrm{A}$ and $\mathrm{Z}$, and for protonation of lumen-exposed carboxyl groups of minor chlorophyll binding proteins (CPs) of the PSII inner antenna. The interaction of $\mathrm{Z}+\mathrm{A}$ and protonated CPs leads to an increased rate constant of heat dissipation for excitation energy in the PSII antenna (Gilmore, 1997; Gilmore et al., 1995).

In maize (Khamis et al., 1990) and spinach (Verhoeven et al., 1997), low $\mathrm{N}$ leaves had a greater proportion of the xanthophyll cycle as $\mathrm{Z}$ and $\mathrm{A}$ at midday and a higher ratio of xanthophyll cycle pigments to total chlorophyll. This supports the general conclusion found in other environmental stresses that thermal dissipation of excitation energy is xanthophyll cycle-dependent. Nevertheless, $\mathrm{N}$ supply did not affect Fv/Fm of dark-adapted leaves, the pool size and the deepoxidation state of the xanthophyll cycle at midday in 'Traveler's Joy' clematis (Clematis vitalba L.) grown at several PPFs (Bungard et al., 1997). Thermal dissipation, however, was not measured in that experiment. The involvement of the xanthophyll cycle in thermal dissipation of excitation energy in apple leaves in response to leaf $\mathrm{N}$ warrants further research.

In summary, light absorption is less in apple leaves with low $\mathrm{N}$ content, but those leaves still have more excess absorbed light than high $\mathrm{N}$ leaves under high light conditions. This is because low $\mathrm{N}$ leaves have low rates of electron transport. As leaf $\mathrm{N}$ content decreases, thermal dissipation of excitation energy is enhanced. This reduces the efficiency with which excitation energy is delivered to open PSII reaction centers, whereby protecting leaves from photooxidation by excess absorbed light.

\section{Literature Cited}

Adams, III, W.W. and B. Demmig-Adams. 1992. Operation of the xanthophyll cycle in higher plants in response to diurnal changes in incident light. Planta 186:390-398.

Adams, III, W.W. and B. Demmig-Adams. 1994. Carotenoid composition and down regulation of photosystem II in three conifer species during the winter. Physiol. Plant. 92:451-458.

Adams, III, W.W. and B. Demmig-Adams. 1995. The xanthophyll cycle and sustained thermal energy dissipation activity in Vinca minor and Euonymus kiautschovicus in winter. Plant Cell Environ. 18:117-127.

Adams, III, W.W., A. Hoehn, and B. Demmig-Adams. 1995a. Chilling temperatures and the xanthophyll cycle. A comparison of warm-grown and overwintering spinach. Austral. J. Plant Physiol. 22:75-85.

Adams, III, W.W., B. Demmig-Adams, A.S. Verhoeven, and D.H. Barker. 1995b. 'Photoinhibition' during winter stress: Involvement of sustained xanthophyll cycle-dependentenergy dissipation. Austral. J.PlantPhysiol. 22:261-276.

Arnon, D.I. 1949. Copper enzymes in isolated chloroplasts: Polyphenoloxidase in Beta vulgaris. Plant Physiol. 24:1-15.

Asada, K. 1996. Radical production and scavenging in the chloroplasts, p. 123-150. In: N.R. Baker (ed.). Photosynthesis and the environment. Kluwer Academic Publishers, Dordrecht, The Netherlands.

Bilger, W. and O. Björkman. 1990. Role of the xanthophyll cycle in photoprotection elucidated by measurements of light-induced absorbance changes, fluorescence and photosynthesis in Hedera canariensis. Photosyn. Res. 25:173-185.

Bungard, R.A., D. McNeil, and J.D. Morton. 1997. Effects of nitrogen on the photosynthetic apparatus of Clematis vitalba grown at several irradiances. Austral. J. Plant Physiol. 24:205-214.

Cheng, L. 1999. Photosynthesis in relation to nitrogen in apple (Malus domestica Borkh.) leaves. PhD diss. Ore. State Univ., Corvallis.

Cheng, L. and L.H. Fuchigami. 2000. $\mathrm{CO}_{2}$ assimilation in relation to 
nitrogen content in apple leaves. J. Hort. Sci. Biotechnol. (in press).

Demmig-Adams, B. and W.W. Adams, III. 1996. Xanthophyll cycle and light stress in nature: Uniform response to excess direct sunlight among higher plant species. Planta 198:460-470.

Demmig-Adams, B., W.W. Adams, III, D.H. Barker, B.A. Logan, D.R. Bowling, and A.S. Verhoeven. 1996. Using chlorophyll fluorescence to assess the fraction of absorbed light allocated to thermal dissipation of excess excitation. Physiol. Plant. 98:253-264.

Demmig-Adams, B., W.W. Adams, III, and S.C. Grace. 1997. Physiology of light tolerance in plants. Hort. Rev. 18:215-246.

Demmig-Adams, B., W.W. Adams, III, B.A. Logan, and A.S. Verhoeven. 1995. Xanthophyll cycle-dependent energy dissipation and flexible photosystem II efficiency in plants acclimated to light stress. Austral. J. Plant Physiol. 22:249-260.

Evans, J.R. 1996. Developmental constraints on photosynthesis: Effects of light and nutrition, p. 281-304. In: N.R. Baker (ed.). Photosynthesis and the environment. Kluwer Academic Publishers, Dordrecht, The Netherlands.

Genty, B., J.M. Briantais, and N.R. Baker. 1989. The relationship between the quantum yield of photosynthetic electron transport and quenching of chlorophyll fluorescence. Biochim. Biophys. Acta 990:87-92.

Genty, B., J. Harbinson, J.M. Briantais, and N.R. Baker. 1990. The relationship between non-photochemical quenching of chlorophyll fluorescence and the rate of photosystem 2 photochemistry in leaves. Photosyn. Res. 25:249-257.

Gilmore, A.M. 1997. Mechanistic aspects of xanthophyll cycle-dependent photoprotection in higher plant chloroplasts and leaves. Physiol. Plant. 99:197-209.

Gilmore, A.M. and O. Björkman. 1994a. Adenine nucleotides and the xanthophyll cycle in leaves. I. Effects of $\mathrm{CO}_{2}$ - and temperature-limited photosynthesis on adenylate energy charge and violaxanthin deepoxidation. Planta 192:526-536.

Gilmore, A.M. and O. Björkman. 1994b. Adenine nucleotides and the xanthophyll cycle in leaves. II. Comparison of the effects of $\mathrm{CO}_{2}$ - and temperature-limited photosynthesis on photosystem II fluorescence quenching, the adenylate energy charge and violaxanthin de-epoxidation in cotton. Planta 192:537-544.

Gilmore, A.M., T.L. Hazlett, and Govindjee. 1995. Xanthophyll cycledependent quenching of photosystem II chlorophyll a fluorescence: Formation of a quenching complex with a short fluorescence lifetime. Proc. Natl. Acad. Sci. USA 92:2273-2277.

Hampson, C.R., A.N. Azarenko, and J.R. Potter. 1996. Photosynthetic rate, flowering, and yield component alteration in hazelnut in response to different light environments. J. Amer. Soc. Hort. Sci. 121:1103-1111.

Horton, P., A.V. Ruban, and R.G. Walters. 1996. Regulation of light harvesting in green plants. Annu. Rev. Plant Physiol. Plant Mol. Biol. 47:655-684.

Khamis, S., T. Lamaze, Y.Lemoine, and C. Foyer. 1990. Adaptation of the photosynthetic apparatus in maize leaves as a result of nitrogen limitation: Relationship between electron transport and carbon assimilation. Plant Physiol. 94:1436-1443.

Koller, D. 1990. Light-driven leaf movements. Plant Cell Environ. 13:615632.

Krall, J.P. and G.E. Edwards. 1992. Relationship between photosystem II activity and $\mathrm{CO}_{2}$ fixation in leaves. Physiol. Plant. 86:180-187.

Massacci, A. and H.G. Jones. 1990. Use of simultaneous analysis of gasexchange and chlorophyll fluorescence quenching for analyzing the effects of water stress on photosynthesis in apple leaves. Trees 4:1-8.

Schreiber, U., W. Bilger, and C. Neubauer. 1994. Chlorophyll fluorescence as a nonintrusive indicator for rapid assessment of in vivo photosynthesis, p. 49-70. In: E.D. Schulze and M.M. Caldwell (eds.). Ecophysiology of photosynthesis. Springer-Verlag, Berlin.

Schuman, G.E., A.M. Stanley, and D. Knudsen. 1973. Automated total nitrogen analysis of soil and plant samples. Proc. Soil Sci. Soc. Amer. 37:480-481.

Sharkey. T.D. 1990. Feedback limitation of photosynthesis and the physiological role of ribulose bisphosphate carboxylase carbamylation. Bot. Mag., Tokyo Spec. Issue 2:87-105.

Thiele, A., G.H. Krause, and K. Winter. 1998. In situ study of photoinhibition of photosynthesis and xanthophyll cycle activity in plants growing in natural gaps of the tropical forest. Austral. J. Plant Physiol. 25:189-195. van Kooten, O. and J.F.H. Snel. 1990. The use of fluorescence nomenclature in plant stress physiology. Photosyn. Res. 25:147-150.

Verhoeven, A.S., W.W. Adams, III, and B. Demmig-Adams. 1996. Close relationship between the state of the xanthophyll cycle pigments and photosystem II efficiency during recovery from winter stress. Physiol. Plant. 96:567-576.

Verhoeven, A.S., B. Demmig-Adams, and W.W. Adams, III. 1997. Enhanced employment of the xanthophyll cycle and thermal energy dissipation in spinach exposed to high light and $\mathrm{N}$ stress. Plant Physiol. 113:817-824.

Woodrow, I.E. and J.A. Berry. 1988. Enzymatic regulation of photosynthetic $\mathrm{CO}_{2}$ fixation in $\mathrm{C}_{3}$ plants. Annu. Rev. Plant Physiol. Plant Mol. Biol. 39:533-594. 